\title{
It's a gas! Pneumatic release of VMT
}

Eye (2017) 31, 347-348; doi:10.1038/eye.2016.229; published online 4 November 2016

Vitreoretinal conferences seldom make the papers. And why would they? Most involve a relatively staid delivery of the clinical evidence; perhaps a few quips and rebuttals here and there, but without the drama of white-hot controversy. That remains the case, but the introduction of ocriplasmin did warm things up, a little.

The build-up to ocriplasmin's launch as a treatment for symptomatic vitreomacular adhesion keenly focussed our attention on whether it would transform the treatment landscape and put vitreoretinal surgeons out of work. The initial excitement for the latest vitreoretinal innovation soon evaporated, to be replaced by a degree of scepticism. ${ }^{1,2}$ Efficacy appeared variable and significant side effects occurred in some patients, including several cases with outer retinal changes postulated to be related to the drug's off-target action on laminins in the interphotoreceptor matrix. While ocriplasmin remains in use, market penetration is far below initial projections.

Yet, an important benefit of ocriplasmin's introduction may be a renewed interest in nonsurgical treatment of vitreomacular traction (VMT) and macular hole.

Enter intravitreal injection of expansile gas as an alternative means of releasing VMT. Or, more accurately, re-enter intravitreal gas (the technique was first reported as a treatment for macular hole in 1995, by Chan et al). ${ }^{3}$

In this issue, Claus et al ${ }^{4}$ report their retrospective series of 20 eyes receiving intravitreal gas injection for the treatment for VMT. Most patients received $0.2 \mathrm{ml}$ of hexafluoroethane $\left(\mathrm{C}_{2} \mathrm{~F}_{6}\right)$ via a 30-gauge needle, combined with anterior-chamber paracentesis.

They instructed the majority of their patients to spend at least some time with their face down, moving their eyes left to right and back, to agitate the gas bubble and promote VMT release (although their data, and the findings of others,

TL Jackson ${ }^{1}$ and DH Steel ${ }^{2,3}$

do not necessarily support the need for ocular calisthenics).

They report a top-line result of $85 \%$ VMT release within 3 months. At 1 month they found $55 \%$ VMT release, which compares favorably with the $26.5 \%$ vitreomacular adhesion release at the 28-day primary end point of the pivotal ocriplasmin trials. ${ }^{5}$

Their results are consistent with those of several other investigators using gas for the treatment of VMT or macular hole. Across a range of previous studies, 39 of 83 eyes $(47.0 \%)$ had anatomic success, defined as no VMT or macular hole and without recourse to PPV. ${ }^{3,6-12}$ Taken together, these studies suggest, but don't prove, that gas may be effective.

If gas was proven safe and effective it has protean advantages. Gas is low-tech, widely available, and the infrastructure to deliver intravitreal injections is already in place. Unlike vitrectomy it does not require vitreoretinal surgeons to deliver treatment, and it is already licensed for intraocular injection (albeit not necessarily for the pneumatic release of VMT). Gas has a favorable safety profile when used as a treatment for other vitreoretinal diseases.

Storage is easy, preparation simple, and there is potentially less variability in action related to its physical rather than proteolytic action. ${ }^{13}$

But before we reignite our enthusiasm and plan to pack away our vitrectors (again), it is reasonable pause for thought. First up, the evidence comes from uncontrolled studies, and, given that VMT may release spontaneously, a control group is important to estimate the magnitude of any therapeutic benefit. Secondly, rare safety events may not yet be evident in the small case series available, and with limited follow-up, long-term safety is unknown.

Claus et al and others report the progression of VMT to macular hole following gas injection..$^{4,11}$ However, development of a macular hole does not necessarily preclude the use of gas, indeed, cases of VMT / stage 1 macular hole are often aptly described as an 'impending' macular hole, and hence development of a macular hole may not always be attributable to gas. There was also

\footnotetext{
${ }^{1}$ King's College London, Department of Ophthalmology, King's College Hospital, London, UK
}

${ }^{2}$ Sunderland Eye Infirmary, Sunderland, UK

${ }^{3}$ Institute of Genetic Medicine, Newcastle University, Newcastle Upon Tyne, UK

\section{Correspondence:} TL Jackson, King's College London, Department of Ophthalmology, King's College Hospital, London SE5 9RS, UK

Tel: +44 (0)20 32993385 . E-mail: t.jackson1@nhs.net 
an appreciable $(5.2 \%)$ rate of macular hole development in the pivotal ocriplasmin trials. ${ }^{5}$

Gas could also cause raised intraocular pressure, central retinal artery occlusion, cataract, retinal breaks, retinal detachment, etc. Claus et al noted that some patients had reduced vision and attributed this to the development of cataract, but they did not offer data in support of this hypothesis, so it might best be regarded as speculative; indeed, it raises the possibility that VMT release can inherently damage vision. Perhaps at least some of the cases of presumed ocriplasmin toxicity reflect structural changes that occur alongside release of VMT? These theoretical safety concerns and uncertainties can in part be mitigated by our experience with pneumatic retinopexy, which shows acceptable safety, but we should not automatically assume that those safety data can be transposed to a different disease.

In conclusion, Claus et al should be congratulated for adding to the body of evidence in support of intravitreal gas for VMT. If gas is as good as it seems we have a very, very cheap treatment with few barriers to adoption, but how about some RCTs first?

\section{Conflict of interest}

TL Jackson has served as a consultant to Thrombogenics and advisor to Alcon. His employer received site payment for participants enrolled on clinical studies sponsored by Alcon. DH Steel has served as an advisor to Alcon. His employer received site payment for participants enrolled on clinical studies sponsored by Alcon and he has received investigator-initiated grant funding from Alcon.

\section{References}

1 Haynes RJ, Yorston D, Laidlaw DA et al. Real world outcomes of ocriplasmin use by members of the British and
Eire Association of Vitreoretinal Surgeons. Eye (Lond) 2017; 31: 107-112.

2 Kim JE. Safety and complications of ocriplasmin: ocriplasmin, ocriplasmin; oh, how safe art thou? JAMA Ophthalmol 2014; 132(4): 379-380.

3 Chan CK, Wessels IF, Friedrichsen EJ. Treatment of idiopathic macular holes by induced posterior vitreous detachment. Ophthalmology 1995; 102(5): 757-767.

4 Claus MG, Feron E, Veckeneer M. Pneumatic release of focal vitreomacular traction. Eye (Lond) 2016 [epub ahead of print].

5 Stalmans P, Benz MS, Gandorfer A et al. Enzymatic vitreolysis with ocriplasmin for vitreomacular traction and macular holes. N Engl J Med 2012; 367(7): 606-615.

6 Costa RA, Cardillo JA, Morales PH, Jorge R, Uno F, Farah ME. Optical coherence tomography evaluation of idiopathic macular hole treatment by gas-assisted posterior vitreous detachment. Am J Ophthalmol 2001; 132(2): 264-266.

7 Chen TC, Yang CH, Yang CM. Intravitreal expansile gas in the treatment of early macular hole: reappraisal. Ophthalmologica 2012; 228(3): 159-166.

8 Jorge R, Costa RA, Cardillo JA, Uno F, Bonomo PP, Farah $\mathrm{ME}$ et al. Optical coherence tomography evaluation of idiopathic macular hole treatment by gas-assisted posterior vitreous detachment. Am J Ophthalmol 2006; 142(5): 869-871.

9 Mori K, Saito S, Gehlbach PL, Yoneya S. Treatment of stage 2 macular hole by intravitreous injection of expansile gas and induction of posterior vitreous detachment. Ophthalmology 2007; 114(1): 127-133.

10 Gupta B, McHugh D. Pneumatic retinopexy for the management of impending macular hole: an optical coherence tomography study. Int Ophthalmol 2011; 31(1): 23-24.

11 Rodrigues IA, Stangos AN, McHugh DA, Jackson TL. Intravitreal injection of expansile perfluoropropane $(\mathrm{c}(3) \mathrm{f}(8))$ for the treatment of vitreomacular traction. Am J Ophthalmol 2013; 155(2): 270-6 e2.

12 Day S, Martinez JA, Nixon PA, Levitan M, Dooner JW, Wong RW et al. Intravitreal sulfur hexafluoride injection for the treatment of vitreomacular traction syndrome. Retina 2016; 36(4): 733-737.

13 Steel DH, Wong D. Ocriplasmin - variable efficacy? Graefes Arch Clin Exp Ophthalmol 2016; 254(7): 1245-1246. 